\title{
Appendacide? Really?
}

\author{
James L. Cox, MD
}

\footnotetext{
From the Division of Cardiac Surgery, Bluhm Cardiovascular Institute, Feinberg School of Medicine, Northwestern University, Chicago, Ill.

Received for publication Feb 25, 2019; revisions received March 15, 2019; accepted for publication March 16 , 2019; available ahead of print May 21, 2019.

Address for reprints: James L. Cox, MD, Division of Cardiac Surgery, Bluhm Cardiovascular Institute, Feinberg School of Medicine, Northwestern University, 201 E Huron St, Chicago, IL 60601 (E-mail: James.Cox@nm. org).

J Thorac Cardiovasc Surg 2020;159:853-6

$0022-5223 / \$ 36.00$

Copyright (c) 2019 by The American Association for Thoracic Surgery

https://doi.org/10.1016/j.jtcvs.2019.03.103
}

I thoroughly enjoyed reading Craig Smith's entertaining Featured Expert Opinion article in the Journal, entitled "Appendacide! Alas, Poor Auricle ...". ${ }^{1}$ My first response was that it seems almost unfair that someone who can write such elegant and witty prose could also be one of the world's great cardiac surgeons. Being a New Yorker, Dr Smith may not be familiar with the old southern adage to "Never kick a cow chip on a hot day." Actually, a book by that title was written by Todd Ordal $^{2}$ a few years ago for the benefit of company chief executive officers, but ... Alas! poor surgeon ... not for us. Not as elegant perhaps as Through the Looking-Glass but instructive nonetheless! Unfortunately, I ignored that adage once as a kid growing up on a southern farm, and I suffered the consequences. My experience fell far short of the lofty standards of a randomized, controlled trial (RCT), but my small observational study $(\mathrm{n}=1)$ was conclusive enough for me! So, even though Dr Smith may be unaware of the "central lesson" of this old adage, I believe that he has kicked a hot cow chip with his recent Appendacide editorial. With all deference to Dr Smith and with as much humility as I am genetically capable of conjuring up (not all that much), allow me to offer a few counterpoints to his entertaining Appendacide editorial.

Dr Smith gently scoffs at the article by Yao and colleagues ${ }^{3}$ by describing their study, which included 75,782 patients, as “... an exhaustive strip-mining operation ...". He also described a similar article by Friedman ${ }^{4}$ as having “... strip-mined a smaller administrative database $(10,524)$ ...". This is certainly a colorful turn of phrase, though perhaps a bit too pejorative in this case. FIRST COW CHIP ALERT! The so-called strip-mining approach is a valid way to evaluate problems that occur with statistical infrequency in clinical medicine, such as strokes due to atrial fibrillation (AF) (60 strokes/100,000 person-years of AF; 95\% confidence limit, 52-70). ${ }^{5}$ Otherwise, we should do away with the Society of Thoracic Surgeons National Adult Cardiac Surgery Database! An alternative approach familiar to the military services is to take advantage of

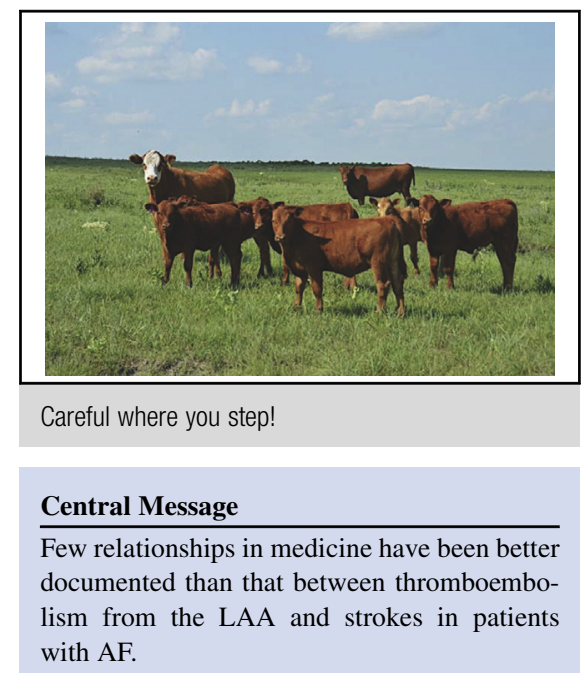

what they call a "target-rich environment." In medical science, this approach is often more productive than the "stripmining" approach because it does not require such huge numbers of patients to answer a specific question. For example, in my personal experience with the Maze procedure for AF, we had a subgroup of approximately 100 patients with AF who previously had strokes that were attributed, rightly or wrongly, to the AF. In terms of the potential for finding left atrial appendage (LAA) thrombi at the time of surgery in patients with AF with a history of stroke, that subgroup clearly qualified as a target-rich environment!

Strip-mining studies have shown that the perioperative stroke rates are increased in patients who develop perioperative AF regardless of the type of cardiac operation performed. ${ }^{6}$ We performed concomitant Maze procedures in patients who were also undergoing multiple other cardiac procedures simultaneously. Obviously, those other cardiac surgery procedures carried their own risks of perioperative stroke with or without the presence of AF. They included coronary artery bypass grafting $(\mathrm{CABG})$, mitral valve repair or replacement (MVR), aortic valve replacement (AVR), CABG/MVR, CABG/AVR, AVR/MVR, CABG/MVR/ AVR, MVR/tricuspid valve repair, CABG/MVR/tricuspid valve repair, Morrow procedures for hypertrophic obstructive cardiomyopathy, atrial septal defect patch closure, sinus venosus atrial septal defect with pulmonary vein reimplantation, persistent left superior vena cava emptying into huge coronary sinuses, removal of a large left atrial septal myxoma, and several patients with cor triatriatum. 
Surprisingly, only 1 perioperative stroke occurred in our entire experience of approximately 500 patients. Some $37 \%$ of our patients had postoperative AF between days 2 and 8 after surgery, so the absence of AF could not have explained the virtual elimination of perioperative strokes. My question is ... How can this lack of perioperative stroke be explained if not on the basis of the removal or closure of the LAA? I have been waiting 20 years for an alternative explanation.

To evaluate the impact of the Maze procedure on longterm stroke rates, Ralph Damiano's group in St Louis reported the 15-year follow-up on my St Louis patients in 2003. ${ }^{7}$ Only 1 stroke occurred over those 15 years despite the fact that $65 \%$ of the patients were not anticoagulated beyond the first 6 to 12 weeks after surgery. Damiano's group later reported on his own patients with virtually identical 10 -year results ( 1 stroke), and $80 \%$ of his patients were not anticoagulated. ${ }^{8}$ It has been argued that because more than $90 \%$ of the patients in both of our groups were $\mathrm{AF}$ free, the very absence of AF was the explanation for the paucity of strokes. ${ }^{9}$ Indeed, that is one possible explanation for the long-term decrease in strokes, but it cannot explain the elimination of the perioperative strokes in the same patients.

Of the LAAs that I personally amputated, removed, and immediately opened from base to tip in the subgroup of approximately 100 patients who had already had preoperative strokes attributed to AF, I found LAA thrombi in only 2 patients. SECOND COW CHIP ALERT! Does this mean that the clots that embolized came from a source located "somewhere else" as suggested in the Appendacide editorial? No thrombus was found in the pulmonary veins, left atrium, or left ventricle, or on the mitral valve in any of those patients. Thus, "somewhere else" would have to be the aortic valve or the ascending aorta because there is nothing else between the pulmonary veins and the carotid arteries. But if the emboli originated from an extracardiac source, why would AF increase the incidence of stroke 5fold? And if LAA thrombi are only markers for thrombi elsewhere, why did our closure (or removal) of the LAA in all those maze patients eliminate perioperative stroke?

THIRD COW CHIP ALERT! Perhaps the near absence of LAA clot in patients with AF with a history of stroke could mean that the clot had formed only once and then the whole thing embolized to the brain. Otherwise, some of it would have remained in the LAA, right? Not so fast. As the prison warden in the movie Cool Hand Luke said, "What we've got here is a failure to communicate." Proper communication requires a logical explanation of how LAA removal eliminated perioperative stroke in extremely highrisk patients, but only $2 \%$ of those patients had LAA thrombi.

The Framingham Study established that patients with AF are 5 times more likely to have a stroke than patients without $\mathrm{AF} .^{10}$ The current concept of strokes associated with $\mathrm{AF}$ is that a thrombus first forms within the trabeculated portion of the LAA, and at some later time, a "fleck" of the thrombus, or even of the entire thrombus itself, embolizes to the brain causing a stroke. Dr Smith clearly accepts this pathophysiologic concept of thromboembolic strokes in patients with AF, but questions that the LAA is the site of the original thrombus because we rarely actually "see" LAA thrombi on transesophageal echocardiography or at surgery. Therefore, he suggests that the contemporary rush to close the LAA for the purpose of reducing strokes associated with AF has no valid scientific basis. It is then implied that LAA closure is more related to the favorable economics of LAA closure than to any benefit that the patient with $\mathrm{AF}$ might receive from the procedure. Whoa! That's a very slippery slope! It begins with a questionable pathophysiologic hypothesis of thromboembolism and ends with " .... the unholy trinity of drive-by surgeons eager to perform procedures, interventional cardiologists eager to own structural heart disease, and manufacturers eager to sell devices to both parties." Before arriving at the bottom of that slippery slope, perhaps we should take a step back and ask if there is a different pathophysiologic explanation for why patients with $\mathrm{AF}$ who have strokes rarely have visible clots in the LAA, whereas the majority of studies in patients with $\mathrm{AF}$ have shown that mechanical closure of the LAA decreases the incidence of stroke. We have provided such an hypothesis on that matter previously, ${ }^{11}$ although thankfully, it did not make it into the Appendacide editorial!

It is generally agreed that "smoke" in the left atrium and LAA on echocardiography is a precursor to the development of a thrombus, and it stands to reason that when we see smoke in the body of the LA, it is likely worse in the LAA. ALTERNATIVE HYPOTHESIS ALERT! I believe that rather than a clot first attaching to the LAA wall and then sending "flecks" off to the brain, the clot simply embolizes as soon as it is formed without first having attached to the LAA wall. This hypothesis would explain the paradox of being able to decrease the stroke rate by closing the LAA, yet rarely finding thrombi in the LAA of patients with AF who have had a stroke. AF has been shown to cause endothelial injury in both atria and to increase the coagulability of blood. ${ }^{12}$ The distal LAA is the only place in the entire cardiovascular system where blood flow is normal during sinus rhythm but instantly becomes static with the onset of AF. Thus, during AF the LAA provides the arterial system's most optimal environment for thrombosis to occur according to Virchow's Triad of tissue injury, hypercoagulability, and severe stasis.

FOURTH COW CHIP ALERT! Just because very few LAA thrombi have ".... ever been caught in the act of embolizing" does not mean that the embolus did not originate and embolize from the LAA. If I develop a 
tooth abscess and subsequent bacterial endocarditis, I am satisfied that the bacteria on my heart valve most likely originated from the tooth abscess even though I didn't actually "catch them in the act" of traveling there. If I have an upper respiratory infection (URI) and develop a fever, I am pretty sure that the URI is causing the fever, although I did not see the bacteria travel to the temperature centers of my brain. If the URI is then treated successfully and the fever disappears, it confirms that the URI was responsible for my fever. If we tally up the locations of all of the thrombi ever found on premortem examination in patients who have had a stroke associated with AF, we find that $95 \%$ of them are in the LAA. Subsequently decreasing the incidence of stroke by closing the LAA increases my conviction that the LAA was responsible for the stroke even though I did not catch the LAA thrombi in the act of embolizing.

FIFTH COW CHIP ALERT! We live in the era of "evidenced-based medicine" in which concepts like the relationship between the LAA and strokes associated with AF can only be "proven" by an RCT. Logical deduction based on clinical observations is assigned the credibility of a cow chip. Ah, but frozen cow chips are different from hot cow chips. So, do we need an RCT to confirm that or can we just accept the logic derived from multiple observational studies conducted by southern farm boys? The question "Do we need an RCT to prove the utility of parachutes when jumping out of airplanes?" is often used as a similarly whimsical argument against requiring an RCT to "prove" medical observations. Of note, an RCT on that very subject was recently reported in the British Medical Journal by Yeh and associates. ${ }^{13}$ Their results showed that "Parachute use did not reduce death or major traumatic injury when jumping from aircraft in the first randomized evaluation of this intervention." There was, however, one confounding factor. The airplanes that they were jumping from were on the ground, not in the air. Oops! Are we to believe that it is actually possible that an RCT could ever lead us to a faulty conclusion because of certain pretrial biases? Perish the thought! The parachute article pointed out that "When beliefs regarding the effectiveness of an intervention exist in the community, randomized trials might selectively enroll individuals with a lower perceived likelihood of benefit, thus diminishing the applicability of the results to clinical practice." This is especially true for RCTs in cardiac surgery where it is virtually impossible to control for all of the variables regarding how a cardiac surgeon conducts a given surgical procedure.

The first RCT designed to determine if closing the LAA would decrease the incidence of stroke was the Left Atrial Appendage Occlusion Study. ${ }^{14}$ It showed no difference in the stroke rate in patients who had no LAA occlusion and those whose LAAs were closed by epicardial suturing techniques or epicardial stapling. But .... epicardial suturing failed to close the LAA in $57 \%$ of patients and surgical stapling left behind residual LAA stumps greater than $1.0 \mathrm{~cm}$ in depth in $38 \%$ that were actually thrombogenic. Of note, however, in those LAAs that were completely closed without an appendage stump by either surgical technique, the stroke rate was decreased by $54 \%$. The 5 -year outcomes of the PROTECT-AF and PREVAIL RCTs showed that the percutaneous Watchman device was noninferior (early) or superior (later) to systemic warfarin anticoagulation in reducing the incidence of AF-related strokes. ${ }^{15}$ Hopefully, the recently completed Left Atrial Appendage Occlusion Study III $\mathrm{RCT}^{16}$ will further clarify the relationship between LAA occlusion and strokes associated with AF.

I agree with Dr Smith's cautionary points relating to blindly closing or removing all LAAs because doing so can be quite detrimental in patients with a stiff left atrium who need the extra capacitance of the LAA. I am less concerned about the effects of LAA closure or removal on overall left atrial function and on the neurohormonal effects of removing or isolating the LAA. The percutaneous endocardial LAA closure devices like the Watchman (Boston Scientific, Marlborough, MA) and Amulet (Abbott, Minneapolis, MN) devices have little effect on atrial natriuretic peptide levels. ${ }^{17}$ However, epicardial LAA occlusion devices, such as the percutaneous LARIAT (SentreHEART Inc, Redwood City, Calif) and the surgical AtriClip (AtriCure, Mason, Ohio) that devascularize the myocardium of the LAA, decrease the atrial natriuretic peptide and other neurohormone levels. However, decreasing the levels of these neurohormones is rarely detrimental, and LAA devascularization is often beneficial because it results in an improvement in the success of $\mathrm{AF}$ ablation by isolating $\mathrm{AF}$ triggers located in the LAA. ${ }^{18}$

In summary, we should be cautious in accepting RCTs as the only way to prove a clinical concept in cardiac surgery. In an elegant essay by Vandenbroucke ${ }^{19}$ discussing the relative importance of observational research and randomized trials, he stated "In our real world, randomized trials can solve problems of 'confounding by indication' in situations where observational research cannot. Still, we may have been deluding ourselves about their unique superiority because they start with much higher prior odds than most observational research .... this may explain the difference in their seeming strength." Our historical dependency on the results obtained from multiple, reproducible, and meticulously performed observational studies, combined with simple logic, has served us well. Not many of our standard practices in cardiac surgery based on observational studies have been shown to be detrimental on the basis of subsequent RCTs. That is why I respectfully disagree with the skepticism of the Appendacide editorial that was directed squarely at the mountain of 
evidence showing that closure of the LAA results in a decreased incidence of stroke associated with AF.

\section{Conflict of Interest Statement}

J.L.C. is an employee of Northwestern University and has the following commercial interests: Adagio Medical, Inc., Laguna Hills, California: Board of Directors, Consultant, Stockholder; Atricure, Inc., Mason, Ohio: Consultant, Stockholder; SentreHEART, Inc., Redwood City, California: Consultant, Stockholder; PAVmed, Inc., New York City, New York: Board of Directors, Stockholder; Lucid Diagnostics, Inc., Cleveland, Ohio: Board of Directors, Stockholder; PotentiaMetrics, Inc., St. Louis, Missouri: Board of Directors, Stockholder.

\section{References}

1. Smith C. Appendacide! Alas, poor auricle .... J Thorac Cardiovasc Surg. 2019; 157:1000-3.

2. Ordal T. Never Kick a Cow Chip on a Hot Day. New York, NY: Morgan James Publishing; 2016.

3. Yao X, Gersh MJ, Holmes DR, Melduni RM, Johnsrud DO, Sangaralingham LR, et al. Association of surgical left atrial appendage occlusion with subsequent stroke and mortality among patients undergoing cardiac surgery. JAMA. 2018; 319:2116-26.

4. Friedman DJ, Piccini JP, Wang T, Zheng J, Malasrie C, Holmes DR, et al. Association between left atrial appendage occlusion and readmission for thromboembolism among patients with atrial fibrillation undergoing concomitant cardiac surgery. JAMA. 2018;319:365-74

5. Hannon N, Sheehan O, Kelly L, Marnane M, Merwick A, Moore A, et al. Stroke associated with atrial fibrillation - incidence and early outcomes in the North Dublin population stroke study. Cerebrovasc Dis. 2009;29:43-9.

6. Creswell LL, Schuessler RB, Cox JL, Rosenbloom M. The hazards of postoperative atrial arrhythmias. Ann Thorac Surg. 1993;56:539-49.
7. Prasad SM, Maniar HS, Camillo CJ, Schuessler RB, Boineau JP, Sundt TM III, et al. The Cox maze III procedure for atrial fibrillation: long-term efficacy in patients undergoing lone versus concomitant procedures. J Thorac Cardiovasc Surg. 2003;126:1822-7.

8. Weimar T, Bailey M, Watanabe Y, Marin D, Maniar H, Schuessler R, et al. The Cox-maze IV procedure for lone atrial fibrillation: a single center experience in 100 consecutive patients. J Thorac Cardiovasc Surg. 2011;31:47-54.

9. Chatterjee S, Alexander JC, Pearson PJ, Feldman T. Left atrial appendage occlusion: lessons learned from surgical and transcatheter experiences. Ann Thorac Surg. 2011;92:2283-92.

10. Wolf PA, Abbott RD, Kannel WB. Atrial fibrillation as an independent risk factor for stroke: the Framingham Study. Stroke. 1991;22:983-8.

11. Cox JL. Mechanical occlusion of the left atrial appendage: is it time to be more aggressive? J Thorac Cardiovasc Surg. 2013;146:1018-27.

12. Lim HS, Willoughby SR, Schultz C, Alasady GC, Lau DH, et al. Effect of atrial fibrillation on atrial thrombogenesis in humans: impact of rate and rhythm. J Am Coll Cardiol. 2013;61:61852-60.

13. Yeh RW, Valsdottir LR, Yeh MW, Shen C, Kramer DB, Strom JB, et al. Parachute use to prevent death and major trauma when jumping from aircraft: randomized controlled trial. Br Med J. 2018;363:k5094.

14. Healey JS, Crystal E, Lamy A, Teoh K, Semelhago L, Hohnloser SH, et al. Left atrial appendage study (LAAOS): results of a randomized controlled pilot study of left atrial appendage occlusion during coronary bypass surgery in patients at risk for stroke. Am Heart J. 2005;150:288-93.

15. Reddy VY, Doshi SK, Kar Saibal, Gibson DN, Price MJ, Huber K, et al; PRE VAIL and PROTECT AF Investigators. 5-year outcomes after left atrial appendage closure: from the PREVAIL and PROTECT AF Trials. J Am Coll Cardiol. 2017:70:2964-75.

16. Whitlock R, Healey J, Vincent J, Brady K, Teoh K, Royse A, et al. Rationale and design of the Left atrial appendage occlusion study (LAAOS) III. Ann Cardiothorac Surg. 2014;3:45-54.

17. Lakkireddy D, Turagam M, Afzai MR, Rajasing J, Atkins D, Dawn B, et al. Left atrial appendage closure and systemic homeostasis: the LAA HOMEOSTASIS study. J Am Coll Cardiol. 2018;71:135-44.

18. Di Biase L, Burkhardt JD, Sanchez J, Mohanty S, Horton R, Gallinghouse GJ, et al. Left atrial appendage: an underrecognized trigger site of atrial fibrillation. Circulation. 2010;122:109-18.

19. Vandenbroucke JP. Observational research, randomized trials, and two views of medical science. PLoS Med. 2008;5:e67. 